\title{
Dietary factors and fluctuating levels of melatonin
}

\author{
Katri Peuhkuri*, Nora Sihvola and Riitta Korpela \\ Institute of Biomedicine, Pharmacology, Medical Nutrition Physiology, University of Helsinki, Helsinki, Finland
}

\begin{abstract}
Melatonin is secreted principally by the pineal gland and mainly at nighttime. The primary physiological function is to convey information of the daily cycle of light and darkness to the body. In addition, it may have other health-related functions. Melatonin is synthesized from tryptophan, an essential dietary amino acid. It has been demonstrated that some nutritional factors, such as intake of vegetables, caffeine, and some vitamins and minerals, could modify melatonin production but with less intensity than light, the most dominant synchronizer of melatonin production. This review will focus on the nutritional factors apart from the intake of tryptophan that affect melatonin levels in humans. Overall, foods containing melatonin or promoting the synthesis of it by impacting the availability of tryptophan, as well those containing vitamins and minerals which are needed as co-factors and activators in the synthesis of melatonin, may modulate the levels of melatonin. Even so, the influence of daytime diet on the synthesis of nocturnal melatonin is limited, however, the influence of the diet seems to be more obvious on the daytime levels.
\end{abstract}

Keywords: melatonin; 6-sulphatoxymelatonin; diet; vegetable; alcohol; B vitamins

Received: 23 January 2012; Revised: 3 May 2012; Accepted: 12 June 2012; Published: 20 July 2012

$\mathrm{M}$ any normal physiological functions occur at specific times of the day. These biological rhythms, called circadian rhythms, are controlled by an endogenous time-keeping system oscillating approximately 24-h cycle under constant conditions $(1,2)$. The master oscillator, which responds to interior and exterior signals, is located in the suprachiasmatic nucleus $(\mathrm{SCN})$ of the anterior hypothalamus in the brain. The most powerful pacemaker is the environmental light-dark cycle. SCN neurons transmit this rhythmic light-dark information to other brain regions and peripheral organs that control many aspects of physiology and behavior, including sleep-wake cycles, cardiovascular activity, the endocrine system, dietary behavior and energy metabolism. These signals are distributed via two main pathways: the direct pathway, which uses the autonomous nervous system and the indirect pathway, which operates via hormonal signals controlled by the SCN, such as the nocturnal peaking secretion of pineal melatonin or the daily increase in adrenal glucocorticoids (3).

Disruption of the circadian rhythm and sleep-wake cycles are considered risk factors for a variety of health problems including obesity and cardiovascular disease $(3,4)$. Several preclinical studies have identified dietary components, such as glucose $(5,6)$, sodium (7), ethanol (8), or caffeine (9) being capable of phase-shifting circadian rhythms by modifying the expression of genetic components of the biological clock, i.e. clock genes. Changes in the circadian cycle modify metabolism, but in addition, alterations in metabolism are also able to entrain physiological clocks, resulting in changes to the rhythms as outlined previously $(1,4)$.

One possible mechanism by which diet can influence circadian rhythms is by modifying the secretion of melatonin. Melatonin is a circulating neurohormone secreted predominantly at night. It is important in conveying the daily cycle of light and darkness to the body, thus regulating circadian rhythms and helping us to fall and stay asleep. In addition to its' regulatory role, melatonin has antioxidative capacity, immunomodulatory potency, and also appears to be protective against a variety of cancers, especially breast cancer, although data is based mostly on observational studies and animal models (10-12). Exogenous melatonin has been used for the treatment of sleep disorders of circadian origin such as jet lag and delayed sleep phase syndrome and as complement of other therapeutic drugs for the treatment of numerous diseases including glaucoma, irritable bowel disease, and certain types of cancers 
mainly to either enhance the therapeutic effect of conventional drug therapy or to reduce their toxicity thus ameliorating the side-effects (13-18). Negative side-effects of exogenous melatonin in abovementioned clinical trials are rare.

The regulating system for the secretion of melatonin is complex. Light is the most influential environmental factor. In addition, melatonin synthesis depends upon availability of its precursor, tryptophan (TRP), which is an essential amino acid and is thus an essential component of the diet. If intake of TRP is severely restricted, synthesis of melatonin is significantly reduced in humans (19). Few studies have explored the influence of other dietary factors on the fluctuation of melatonin levels, for example the intake of certain food items or the availability of nutrients. This narrative review will focus on the nutritional factors apart from the intake of TRP that affect melatonin levels in humans. We used the electronic bibliographical database PubMed until April 2012 (without any methodological restrictions), to identify studies using the following keywords: melatonin, 6-sulphatoxymelatonin, diet, vegetable, alcohol, and B vitamins. In addition, we reviewed the references of identified studies and of selected narrative review articles.

\section{Synthesis of melatonin}

The synthesis and physiological function of melatonin have been recently described accurately in several review articles and are here only very briefly summarized $(10,20-25)$.

Melatonin is a neurotransmitter secreted predominantly by the pineal gland. There are extra-pineal sites of melatonin production, such as the retina and the gut. Even if the synthesis of melatonin in these extra-pineal sites contribute to the total concentration of melatonin, the physiological significance of these sites is uncertain.

Melatonin is synthesized from its precursor, the essential amino acid TRP (Fig. 1). The rate of melatonin formation depends on the activity of enzymes - arylalkylamine$\mathrm{N}$-acetyltransferase (AANAT) and to a lesser extent, tryptophan hydroxylase (TPH). AANAT is represented mostly in the pineal gland where its activity is controlled by SCN. Activity of pineal TPH fluctuates in a clock-driven circadian rhythm, which reaches its highest levels during the night.

Melatonin synthesis is controlled by both an endogenous circadian clock and by environmental light. Light is the dominant environmental factor that controls its synthesis. Pineal melatonin levels begin increasing in the

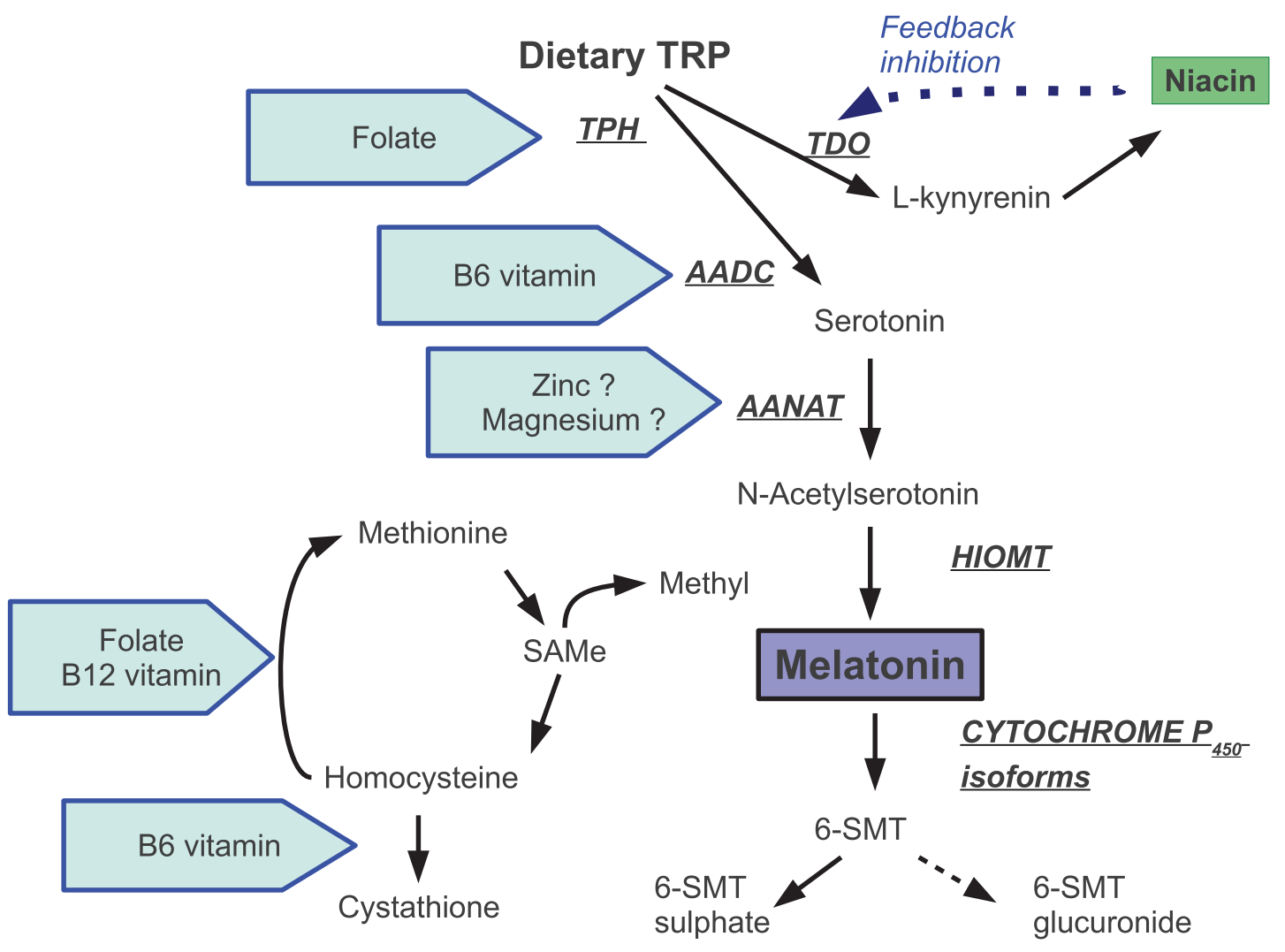

Fig. 1. The synthetic pathway and metabolism of melatonin and possible sites for some nutrients to influence on the synthesis. Enzymes are in underlined capital letters in italics. TRP, tryptophan; TPH, tryptophan hydroxylase; TDO, tryptophan dioxygenase; AADC, aromatic aminoacid decarboxylase; AANAT, arylalkylamone-N-acetyltransferase; HIOMT, hydroxyindole-O-methyltransferase; 6-SMT, 6-sulphatoxymelatonin; SAMe, S-adenosylmethionine. 
late evening, reaching the maximum in the early hours between 2:00 and 4:00 a.m., followed by a slow decline to lower daytime levels. Daytime levels of melatonin are barely detectable. In addition to sunlight, artificial indoor lighting can be bright enough to prevent the nocturnal release of melatonin.

Normal production of melatonin can vary considerably between individuals. In general, melatonin production decrease with aging. Among the other factors that have been most consistently linked to modified melatonin levels are disrupted light-dark cycles, night work and being overweight. In addition, it has been demonstrated that some nutritional factors could also modify melatonin production, however less intensely. Weather dietary factors contribute only to the pineal production of melatonin or also to the extra-pineal sites such as the gastrointestinal production is not known.

Once synthesized, melatonin is not stored in producing cells, but is quickly released into the blood and begins circulation. Thus, the concentration in plasma faithfully reflects pineal secretion. In addition melatonin concentration can be measured in other body fluids as saliva and urine. Saliva levels are about $40 \%$ of those in plasma. Endogenous nocturnal melatonin production has been estimated to be about $10-80 \mu \mathrm{g}$ per night, the daytime production being significantly less.

The metabolism of melatonin is rapid, and its half-life in humans varies between 10 and $60 \mathrm{~min}$ following exogenous administration. It is deactivated mostly by the liver and excreted in urine. Urinary metabolite, 6-sulphatoxymelatonin (6-SMT) reflects the plasma melatonin profile and can be used for evaluation of melatonin status. In urine, $50-80 \%$ of 6-SMT appears in the overnight sample.

\section{Dietary compounds}

There are several studies indicating dietary influence on the synthesis or the concentration of melatonin.

\section{Energy restriction}

Strong influence of food on melatonin synthesis is detected in studies of subjects undergoing periods of fasting. Energy restriction reduces the nocturnal secretion of melatonin although the number of human studies proving this is limited. Short-term voluntary fasting by total rejection of food or with very limited intake of energy ( $<300 \mathrm{kcal}$ per day) from 2 to 7 days reduces melatonin concentration in the blood by about $20 \%$ (26-28). In these studies, however, no changes were noticed in the excreted metabolites of melatonin in urine. Glucose supplementation during short-term fasting returns the decreased melatonin concentration to normal, suggesting that human pinealocytes, or other producing cells, require a certain minimal amount of glucose delivery to function normally $(27,28)$.

\section{Edible plants and plant-based products}

Some food items, especially edible plants, contain melatonin and its precursor TRP as well. Actually, the presence of melatonin in plants is universal, although with widely varied concentrations from picograms to micrograms per gram of plant tissue (29). Melatonin has been detected in notable amounts for example in tomatoes, olives, barley, rice and walnuts (Table 1) (29-40). Recent studies have uncovered that melatonin concentrations differ not only among plant species, but also within varieties of the same species. In grapes, for example, cultivars Nebbiolo and Croatina have very high melatonin levels, about $0.8-0.9 \mathrm{ng} / \mathrm{g}$, whereas Cabernet franc contains only $0.005 \mathrm{ng} / \mathrm{g}$. Thus, in a glass of wine, the concentration of melatonin may vary considerably, from picograms to many nanograms per milliliter $(41,42)$.

The bioavailability of plant-based melatonin has been demonstrated mainly in animals but also in humans (30, $35,43)$. It has been measured as increased blood concentration or heightened amounts of excreted urinary 6-SMT after the ingestion of melatonin-containing products, such as vegetables or barley-based beer $(43,44)$. Even some dose dependency has been noticed - the mean urinary 6-SMT was $16 \%$ higher in Japanese women within the highest quartile of vegetable intake compared to those with the lowest intake (45). However, vegetables and grain products contain large amounts of vitamins and minerals. Thus, even if increased levels of melatonin have been noticed in these studies, it cannot be excluded that the increase is due to boosted endogenous melatonin synthesis by the possible stimulatory effect of ingested products instead of absorbed dietary melatonin only.

In addition to wine, remarkably high melatonin concentrations have been detected in coffee beans as was outlined previously $(29,35)$. Although a cup of coffee is estimated to contain even as much as $40 \mu \mathrm{g}$ of melatonin, corresponding the nocturnal endogenous production, the general effect in the circulating melatonin concentration may differ, since coffee contains caffeine which may

Table 1. Some examples of melatonin content in plants and foods measured by immunological and chromatographic techniques

\begin{tabular}{lll}
\hline Plant/food & \multicolumn{1}{c}{ Melatonin } & Reference \\
\hline Tomato & $3-114 \mathrm{ng} / \mathrm{g}$ & 32,37 \\
Walnuts & $3-4 \mathrm{ng} / \mathrm{g}$ & 30 \\
Cereals (rice, barley) & $300-1,000 \mathrm{pg} / \mathrm{g}$ & 39 \\
Strawberry & $\mathrm{I}-1 \mathrm{I} \mathrm{ng} / \mathrm{g}$ & 32 \\
Olive oil & $53-119 \mathrm{pg} / \mathrm{ml}$ & 34 \\
Wine & $50-230 \mathrm{pg} / \mathrm{ml}$ & 32,36 \\
Beer & $52-170 \mathrm{pg} / \mathrm{ml}$ & 43 \\
Cow's milk (unprocessed) & $3-25 \mathrm{pg} / \mathrm{ml}$ & 38,40 \\
Nighttime milk & $10-40 \mathrm{ng} / \mathrm{ml}$ & 62 \\
\hline
\end{tabular}


reduce endogenous nocturnal melatonin levels. Results in clinical studies are conflicting. In two short-term studies, a single dose of $200 \mathrm{mg}$ caffeine capsules decreased nighttime melatonin secretion, whereas a significant increase of $32 \%$ was observed in another study (46-48). In still another study, subjects were administered repeated $400 \mathrm{mg}$ doses of caffeine capsules at 1-week intervals. Analysis yielded a slight trend of 7\% reduction of nighttime melatonin levels in healthy young adults (49). When caffeine was administered to study subjects via coffee, reduction of more than $50 \%$ was found in nighttime 6-SMT excretion compared with decaffeinated coffee in another small study (50).

Caffeine has both the stimulatory and inhibitory mechanisms affecting the levels of melatonin. Which of these dominate in normal healthy subjects is not clear since hypothesis of mechanisms have been tested mostly in vitro and by using animal models. Caffeine may alter the expression level of clock genes either up-regulating or down-regulating clock gene amplitudes (51, 52). Caffeine acts as an adenosine receptor antagonist. Adenosine increases intracellular cAMP levels via adenosine receptor, which increases the production of AANAT, the rate limiting enzyme in melatonin synthesis (53). Thus as adeosine receptors are blocked by caffeine, the synthesis of melatonin decreases. In addition caffeine may also reduce the break-down of melatonin. Caffeine and melatonin compete for the same metabolizing liver cytochrome P450 enzymes, resulting in higher serum levels of melatonin after large doses of caffeine $(48,54)$.

There are significant differences in before mentioned studies in their designs, in timing and dosing of caffeine as well as sampling and analyzing melatonin and its metabolite. In addition, subjects were either sleepdeprived or not, which greatly modify synthesis of melatonin and can at least partly explain the differences. If study subjects include both males and females, it may also have an influence on the results, since menstruation has been reported to modify such levels, while oral contraceptives have been found to increase nighttime melatonin levels due to inhibiting catalyzing enzymes in the liver (55-58).

\section{Nighttime milk}

Melatonin is a natural compound found in milk. Concentration of melatonin exhibits a marked daily rhythm, with increasing concentrations in milk produced at night $(40,59)$. This phenomenon seems to be universal amongst mammals.

Since milk is the primary component of an infant's diet, and nighttime lactation confirms the nutritional adequacy, melatonin content of nighttime milk may have further physiological relevance. This theory may benefit from further study, but it seems plausible that maternal melatonin may pass through milk to the infant resulting in improved nocturnal sleep, although this is based on a very limited number of observations (59). In addition, if TRP-enriched commercial infant milk formula is served at night, improvements in sleep parameters and increased urinary metabolites of serotonin were observed, suggesting increased use of serotonin to produce melatonin $(60,61)$.

Studies showing the influence of the melatonin content of cow's milk on the fluctuation of melatonin levels in adults are even scarcer. In institutionalized elderly subjects, commercial milk was replaced with melatonin-rich nighttime milk in a double-blind study (62). The ingested total amount of 10-20 ng melatonin from nighttime milk is, however, such a small dose divided into several meals, that physiological significance of it is hard to understand. Morning activity of subjects, however, was significantly increased, indicating some difference between normal commercial milk and nighttime milk, of which the content of melatonin is most obvious.

\section{Alcohol}

Conclusions regarding the influence of alcohol on melatonin levels have been found to be inconsistent. Both acute and chronic consumption of alcohol at a level corresponding to 'social drinking' (10-100 g of ethanol per day) reduce melatonin levels in the blood and in the saliva in three small studies of healthy volunteers (63-65), but not in a fourth study (66). In addition to absolute amount of ethanol, other properties of alcoholic beverages may also have an influence on the overall effect. As mentioned above, wine and beer contain melatonin, and consequently may have additional influence on detectable melatonin levels in the body. In a study of strong beer (alcoholic content of 7.2\%), 45 min after a single dose of $330 \mathrm{ml}$ for women and $660 \mathrm{ml}$ for men, corresponding doses of 24-48 g of ethanol, melatonin level in serum was significantly elevated in a small study with seven healthy subjects (43). This increase was explained by the researchers by the melatonin content of beer.

The influence of alcohol on urinary metabolites of melatonin, however, conflicts with these findings. Even if single or repeated doses of alcohol in the evening reduces the nocturnal melatonin secretion to the blood dosedependently, no corresponding changes in 9-12 h urinary excretion of melatonin metabolites were noticed $(63,64$, 67). In these studies healthy participants - males and females - received doses varying from 15-120 g ethanol per day either as single or repeated daily doses. However, in a large study with over 200 healthy women between the ages of 20 and 74, it was found that the nocturnal urinary concentration of the 6-SMT decreased dose-dependently with increasing consumption of alcoholic beverages in the preceding 24-h period (68). A categorical analysis 
revealed no effect of one drink (on over 70\% of observed days), but a $9 \%$ reduction with two drinks, a $15 \%$ reduction with three drinks, and a $17 \%$ reduction with four or more drinks (on only $2 \%$ of observed days). This was shown also after taking into account the effects of age, number of daily hours of darkness, use of medications that affect melatonin levels and body mass index.

Thus, alcohol consumption seems to reduce the melatonin concentration in the blood, but whether there is an association between urinary melatonin metabolites and alcohol is not as clear, perhaps due to varied beverages and doses used and differences in methods for urine collection as well as ethanol-based metabolic differences. Several possibilities have been hypothesized to explain how ethanol inhibits melatonin secretion. Hypotheses vary from disturbed sleep patterns and loss of daily rhythm caused by alcohol use to reduced TPH activity to phase delay in AANAT gene expression and activity to disturbed steps in the synthesis or excretion of melatonin $(64,69)$. In addition, ethanol decreases TRP levels in plasma resulting in a short-term decrease in the availability of TRP. A small amount of glucose is needed in the synthesis of melatonin. Since ethanol has properties that decrease blood-glucose levels, it has been speculated that an insufficient amount of glucose in pinealocytes would explain the reduced levels of melatonin. The mechanisms behind these remain to be studied further.

\section{Availability of nutrients}

Evidence of nutrients' influence on melatonin synthesis tends to vary. There are some studies, based mostly on animal evidence, which prove the importance of $\mathrm{B}$ vitamins, magnesium, zinc and polyunsaturated fatty acids.

Folate, magnesium and zinc deficiencies have been linked with lower melatonin levels in rodents and in one rodent study, vitamin B6, either alone or in combination with zinc, increased plasma melatonin (70-73). Folate and B6 vitamin are supposed to boost the formation of serotonin from TRP as coenzymes. Zinc and magnesium, instead, are supposed to enhance the formation of melatonin from serotonin by binding to AANAT enzyme, thus activating it and increasing the affinity of serotonin for binding to AANAT $(74,75)$. In humans, the role of these vitamins and minerals is less well studied in this connection.

In a large study of nearly 300 Japanese women, folate intake was not connected with urinary excretion of 6SMT levels (45). Urinary 6-SMT, however, associated positively clearly with intake of all vegetables and especially with green and yellow vegetables. In a Nurses' Health Study of about 1,000 US women, no association was found between the high intake of various nutrients, such as folate, vitamin B6 and zinc and increased urinary melatonin excretion (76). Besides marginal positive associations between orange juice, tomato and dairy cream consumption and urinary 6-SMT, only meat consumption was significantly and inversely associated with urinary 6-SMT in this large study. Neither of these studies, however, reported the vitamin status of the subjects, only their calculated dietary intake.

In a small study of 12 healthy men, orally-supplemented pyridoxine (one vitamers of vitamin B6) as a dose of $100 \mathrm{mg}$ in the evening hours had no effect on nocturnal melatonin levels in the blood (77). Nocturnal melatonin levels in the blood, however, doubled in over 100 small children between the ages of 18 months and 8 years when pyridoxine was administered at night intravenously at doses of $3 \mathrm{mg} / \mathrm{kg}$ (78). Any possible deficiency of pyridoxine in these hospitalized children was not reported.

Reliable clinical evidence of boosted melatonin secretion following the ingestion of cations, magnesium or zinc, does not yet exist. In a study of 10 healthy men, a single intravenous dose of magnesium sulphate was found to have no effect on the release of melatonin (79). No correlation, however, between serum magnesium and melatonin levels was found in patients with intervertebral disc herniation. Instead, a clear positive correlation between serum zinc and melatonin level was found (80).

The pineal gland contains high levels of $n-6$ and $n-3$ polyunsaturated fatty acids (PUFA), especially arachidonic acid and docosahexaenoic acid (DHA) (81). There is some evidence that fatty acid status can influence melatonin synthesis. In rodents, an n-3 deficient diet reduces nighttime melatonin secretion, which returns to normal with supplemented DHA $(82,83)$. Based on animal experiments, the rhythm of AANAT activity may be altered by $n-3$ status and n-3/n- 6 ratio, as well as these may modify the activities of membrane-bound proteins including enzymes, receptors and transporter proteins (81).

We did not find any similar PUFA studies with humans. The only clinical study to measure the importance of dietary PUFA on melatonin levels in humans as yet found is a study of insomnia patients (84). Subjects ingested dietary supplements in capsule form containing soy oil, cade oil, humulus lupus extract and soy lecithin daily for a month immediately before sleep. Neither this supplement nor placebo capsules containing olive oil had any influence on urinary excretion of 6-SMT (84).

\section{Clinical relevance and conclusions}

Melatonin secretion is strongly related to the duration of darkness. Its most definitive physiological role is to convey information to the body about day length for a variety of physiological functions. In addition to melatonin's role as an endogenous synchronizer, growing 
evidence suggests its anti-oxidative activity as well as its having a role in modulating immune responses. At present, a growing interest is focused on the validity of the anti-tumor mechanisms of melatonin.

Synthesis of melatonin requires tryptophan as a precursor as well as a smoothly functioning cascade of several enzyme-based reactions, first to compose serotonin and subsequently melatonin. Several vitamins and minerals act as co-factors and activators in these processes, thus a clear deficiency of needed nutrients may restrict the synthesis. Severe deficiencies, however, are rare in western countries apart from some subgroups. In addition, fluctuating melatonin levels can be boosted by ingesting products containing melatonin. The bioavailability of plant-based melatonin is evident, at least in rodents, and could explain some health benefits of vegetables, fruits and grain products.

Diet and nutrients modulate fluctuating melatonin levels, but the influence is minor if compared with the power of the light-dark cycle. Other health-related lifestyle factors such as body weight, which is connected to diet, may have as much effect on melatonin levels as specific dietary choices. Thus, the health benefits of dietdriven melatonin boosts seem not to be the product of any single food or nutrients present in the diet. In general, diets rich in vegetables, fruits and grain products contain considerable levels of dietary melatonin. Vitamins and minerals contribute to the synthesis of endogenous melatonin while the body is active. Even so, the influence of daytime diet on the synthesis of nocturnal melatonin is very limited, however, the influence of diet seems to be more obvious on the daytime levels of melatonin.

\section{Conflict of interest and funding}

The authors declare no conflict of interest regarding this review. They have not received any funding or benefits from industry, but K.P. and N.S. get support from The SalWe Research Program for Mind and Body (Tekes The Finnish Funding Agency for Technology and Innovation grant 1104/10).

\section{References}

1. Maury E, Ramsey KM, Bass J. Circadian rhythms and metabolic syndrome: from experimental genetics to human disease. Circ Res 2010; 106: 447-62. http://www.ncbi.nlm.nih.gov/ pmc/articles/PMC2837358/?tool=pubmed [cited 20 Dec 2011].

2. Dibner C, Schibler U, Albrecht U. The mammalian circadian timing system: organization and coordination of central and peripheral clocks. Annu Rev Physiol 2010; 72: 517-49. http:// www.annualreviews.org/doi/full/10.1146/annurev-physiol-021909135821?url_ver $=$ Z39.88-2003\&rfr_id=ori:rid:crossref.org\&rfr dat $=$ cr_pub\%3dpubmed [cited 28 Dec 2011].

3. Challet E, Mendoza J. Metabolic and reward feeding synchronises the rhythmic brain. Cell Tissue Res 2010; 341: 1-11. http://www.springerlink.com/content/7038075014738018/ [cited 28 Dec 2011].
4. Froy O. Metabolism and circadian rhythms - implications for obesity. Endocr Rev 2010; 31: 1-24. http://edrv.endojournals.org/ content/31/1/1.long [cited 20 Dec 2011].

5. Hirota T, Okano T, Kokame K, Shirotani-Ikejima H, Miyata T, Fukada Y. Glucose down-regulates Per1 and Per2 mRNA levels and induces circadian gene expression in cultured Rat-1 fibroblasts. J Biol Chem 2002; 277: 44244-51. http:// www.jbc.org/content/277/46/44244.long [cited 28 Dec 2011].

6. Iwanaga H, Yano M, Miki H, Okada K, Azama T, Takiguchi $\mathrm{S}$, et al. Per2 gene expressions in the suprachiasmatic nucleus and liver differentially respond to nutrition factors in rats. JPEN J Parenter Enteral Nutr 2005; 29: 157-61. http://pen.sagepub. com/content/29/3/157.long [cited 29 Dec 2011].

7. Mohri T, Emoto N, Nonaka H, Fukuya H, Yagita K, Okamura $\mathrm{H}$, et al. Alterations of circadian expressions of clock genes in Dahl salt-sensitive rats fed a high-salt diet. Hypertension 2003; 42: 189-94. http://hyper.ahajournals.org/content/42/2/189.long [cited 28 Dec 2011].

8. Spanagel R, Rosenwasser AM, Schumann G, Sarkar DK. Alcohol consumption and the body's biological clock. Alcohol Clin Exp Res 2005; 29: 1550-7. http://onlinelibrary.wiley.com/ doi/10.1097/01.alc.0000175074.70807.fd/abstract;jsessionid $=$ B643DEE45B27358C01251B642C561311.d04t02 [cited 29 Dec 2011].

9. Sherman H, Gutman R, Chapnik N, Meylan J, le Coutre J, Froy O. Caffeine alters circadian rhythms and expression of disease and metabolic markers. Int $\mathrm{J}$ Biochem Cell Biol 2011; 43: 829-38. http://www.sciencedirect. com/science/article/ pii/S1357272511000641 [cited 5 Jan 2012].

10. Zawilska JB, Skene DJ, Arendt J. Physiology and pharmacology of melatonin in relation to biological rhythms. Pharmacol Rep 2009; 61: 383-410. http://www.if-pan.krakow.pl/pjp/pdf/ 2009/3_383.pdf [cited 28 Dec 2011].

11. Mediavilla MD, Sanchez-Barcelo EJ, Tan DX, Manchester L, Reiter RJ. Basic mechanisms involved in the anti-cancer effects of melatonin. Curr Med Chem 2010; 17: 4462-81. http://www. benthamdirect.org/pages/content.php?CMC/2010/00000017/ 00000036/0004C.SGM [cited 12 Jan 2012].

12. Grant SG, Melan MA, Latimer JJ, Witt-Enderby PA. Melatonin and breast cancer: cellular mechanisms, clinical studies and future perspectives. Expert Rev Mol Med 2009; 11: e5. http://journals.cambridge.org/action/displayAbstract?fromPage $=$ online\&aid $=3754536$ [cited 12 Jan 2012].

13. Buscemi N, Vandermeer B, Hooton N, Pandya R, Tjosvold L, Hartling L, et al. The efficacy and safety of exogenous melatonin for primary sleep disorders. A meta-analysis. J Gen Intern Med 2005; 20: 1151-8. http://www.ncbi.nlm.nih.gov/ pmc/articles/PMC1490287/?tool=pubmed [cited 28 Dec 2011].

14. Buscemi N, Vandermeer B, Hooton N, Pandya R, Tjosvold L, Hartling L, et al. Efficacy and safety of exogenous melatonin for secondary sleep disorders and sleep disorders accompanying sleep restriction: meta-analysis. BMJ 2006; 332: 385-93. http://www.ncbi.nlm.nih.gov/pmc/articles/PMC1370968/?tool= pubmed [cited 28 Dec 2011].

15. van Geijlswijk IM, Korzilius HPLM, Smits MG. The use of exogenous melatonin in delayed sleep phase disorder: a meta-analysis. Sleep 2010; 33: 1605-14. http://www.ncbi.nlm. nih.gov/pmc/articles/PMC2982730/?tool=pubmed [cited 5 Jan 2012].

16. Mills E, Wu P, Seely D, Guyatt G. Melatonin in the treatment of cancer: a systematic review of randomized controlled trials and meta-analysis. J Pineal Res 2005; 39: 360-6. http:// onlinelibrary.wiley.com/doi/10.1111/j.1600-079X.2005.00258.x/ abstract [cited 28 Dec 2011].

17. Seely D, Wu P, Fritz H, Kennedy DA, Tsui T, Seely AJ, et al. Melatonin as adjuvant cancer care with and without 
chemotherapy: a systematic review and meta-analysis of randomized trials. Integr Cancer Ther 2011 October 21 [Epub ahead of print]. http://ict.sagepub.com/content/early/2011/10/15/ 1534735411425484.abstract [cited 20 Apr 2012].

18. Sánchez-Barceló EJ, Mediavilla MD, Tan DX, Reiter RJ. Clinical uses of melatonin: evaluation of human trials. Curr Med Chem 2010; 17: 2070-95. http://www.ingentaconnect.com/content/ben/ cmc/2010/00000017/00000019/art00006 [cited 20 Apr 2012].

19. Zimmermann RC, McDougle CJ, Schumacher M, Olcese J, Mason JW, Heninger GR, et al. Effects of acute tryptophan depletion on nocturnal melatonin secretion in humans. J Clin Endocrinol Metab 1993; 76: 1160-4. http://jcem.endojournals. org/content/76/5/1160.long [cited 28 Dec 2011].

20. Reiter RJ, Tan DX, Fuentes-Broto L. Chapter 8 - Melatonin: a multitasking molecule. Prog Brain Res 2010; 181: 127-51. http:// www.sciencedirect.com/science/article/pii/S0079612308810084 [cited 19 Dec 2011].

21. Hardeland R. Melatonin, hormone of darkness and more: occurrence, control mechanisms, actions and bioactive metabolites. Cell Mol Life Sci 2008; 65: 2001-18. http://www.springerlink. com/content/w781036u85742708/ [cited 28 Dec 2011].

22. Claustrat B, Brun J, Chazot G. The basic physiology and pathophysiology of melatonin. Sleep Med Rev 2005; 9: 11-24. http://www.sciencedirect.com/science/article/pii/S1087079204000735 [cited 28 Dec 2011].

23. Karasek M, Winczyk K. Melatonin in humans. J Physiol Pharmacol 2006; 57(Suppl 5): S19-39. http://www.jpp.krakow. pl/journal/archive/11_06_s5/pdf/19_11_06_s5_article.pdf [cited 28 Dec 2011].

24. Bubenik GA. Gastrointestinal melatonin: localization, function, and clinical relevance. Dig Dis Sci 2002; 47: 2336-48. http:// www.springerlink.com/content/r47518675jw057j0/ [cited $22 \mathrm{Apr}$ 2012].

25. de Almeida EA, Di Mascio P, Harumi T, Spence DW, Moscovitch A, Hardeland R, et al. Measurement of melatonin in body fluids: standards, protocols and procedures. Childs Nerv Syst 2011; 27: 879-91. http://www.springerlink. com/content/0256-7040/27/6/ [cited 20 Apr 2012].

26. Michalsen A, Schlegel F, Rodenbeck A, Lüdtke R, Huether G, Teschler H, et al. Effects of short-term modified fasting on sleep patterns and daytime vigilance in non-obese subjects: results of a pilot study. Ann Nutr Metab 2003; 47: 194-200. http:// content.karger.com/produktedb/produkte.asp?DOI=70485\&typ= pdf [cited 29 Dec 2011].

27. Röjdmark S, Rössner S, Wetterberg L. Effect of short-term fasting on nocturnal melatonin secretion in obesity. Metab Clin Exp 1992; 41: 1106-9.

28. Röjdmark S, Wetterberg L. Short-term fasting inhibits the nocturnal melatonin secretion in healthy man. Clin Endocrinol (Oxf) 1989; 30: 451-7.

29. Tan DX, Hardeland R, Manchester LC, Korkmaz A, Ma S, Rosales-Corral S, et al. Functional roles of melatonin in plants, and perspectives in nutritional and agricultural science. J Exp Bot 2011: e1-21. http://www.ncbi.nlm.nih.gov/pubmed/ 22016420 [cited 20 Dec 2011].

30. Reiter RJ, Manchester LC, Tan DX. Melatonin in walnuts: influence on levels of melatonin and total antioxidant capacity of blood. Nutrition 2005; 21: 920-4. http://www.sciencedirect. com/science/article/pii/S0899900705001632 [cited 20 Dec 2011].

31. Mercolini L, Mandrioli R, Raggi MA. Content of melatonin and other antioxidants in grape-related foodstuffs: measurement using a MEPS-HPLC-F method. J Pineal Res 2011 [Epub ahead of print]. http://www.ncbi.nlm.nih.gov/pubmed/22017461 [cited 20 Dec 2011].

32. Iriti M, Varoni EM, Vitalini S. Melatonin in traditional Mediterranean diets. J Pineal Res 2010; 49: 101-5. http://
onlinelibrary.wiley.com/doi/10.1111/j.1600-079X.2010.00777.x/ abstract [cited 20 Dec 2011].

33. Ramakrishna A, Giridhar P, Sankar KU, Ravishankar GA. Melatonin and serotonin profiles in beans of Coffea species. J Pineal Res 2012; 52: 470-6. http://www.ncbi.nlm.nih.gov/ pubmed/22017393 [cited 20 Dec 2011].

34. de la Puerta C, Carrascosa-Salmoral MP, García-Luna PP, Lardone PJ, Herrera JL, Fernández-Montesinos R, et al. Melatonin is a phytochemical in olive oil. Food Chem 2007; 104: 609-12.

35. Reiter RJ, Tan DX, Manchester LC, Simopoulos AP, Maldonado MD, Flores LJ, et al. Melatonin in edible plants (phytomelatonin): identification, concentrations, bioavailability and proposed functions. World Rev Nutr Diet 2007; 97: 211-30.

36. Rodriguez-Naranjo MI, Gil-Izquierdo AG, Troncoso AM, Cators E, Garcia-Parilla MC. Melatonin: a new bioactive compound in wine. J Food Compost Anal 2011; 24: 603-8. http:// www.sciencedirect.com/science/article/pii/S0889157511000263 [cited 22 Apr 2012].

37. Sturtz M, Cerezo AB, Cantos-Villar E, Garcia-Parrilla MC. Determination of the melatonin content of different varieties of tomatoes (Lycopersicon esculentum) and strawberries (Fragaria ananassa). Food Chem 2011; 127: 1329-34. http:// www.sciencedirect.com/science/article/pii/S030881461100197X [cited 15 June 2012].

38. Jouan PN, Pouliot Y, Gauthier SF, Laforest JP. Hormones in bovine milk and milk products: a survey. Int Dairy J 2006; 16: 1408-14. http://www.sciencedirect.com/science/article/pii/ S0958694606001506 [cited 25 Apr 2012].

39. Hattori A, Migitaka H, Iigo M, Itoh M, Yamamoto K, OhtaniKaneko R, et al. Identification of melatonin in plants and its effects on plasma melatonin levels and binding to melatonin receptors in vertebrates. Biochem Mol Biol Int 1995; 35: 627-34.

40. Castro N, Spengler M, Lollivier V, Wellnitz O, Meyer HHD, Bruckmaier RM. Diurnal pattern of melatonin in blood and milk of dairy Cows. Milchwiss-Milk Sci Int 2011; 66: 352-3.

41. Iriti M, Faoro F. Bioactivity of grape chemicals for human health. Nat Prod Commun 2009; 4: 611-34.

42. Stege PW, Sombra LL, Messina G, Martinez LD, Silva MF. Determination of melatonin in wine and plant extracts by capillary electrochromatography with immobilized carboxylic multi-walled carbon nanotubes as stationary phase. Electrophoresis 2010; 31: 2242-8. http://onlinelibrary.wiley.com/ doi/10.1002/elps.200900782/abstract [cited 20 Dec 2011].

43. Maldonado MD, Moreno H, Calvo JR. Melatonin present in beer contributes to increase the levels of melatonin and antioxidant capacity of the human serum. Clin Nutr 2009; 28: 188-91. http://www.sciencedirect.com/science/article/ pii/S0261561409000399 [cited 20 Dec 2011].

44. Oba S, Nakamura K, Sahashi Y, Hattori A, Nagata C. Consumption of vegetables alters morning urinary 6-sulfatoxymelatonin concentration. J Pineal Res 2008; 45: 17-23. http://onlinelibrary. wiley.com/doi/10.1111j.1600-079X.2007.00549.x/abstract [cited 20 Dec 2011].

45. Nagata C, Nagao Y, Shibuya C, Kashiki Y, Shimizu H. Association of vegetable intake with urinary 6-sulfatoxymelatonin level. Cancer Epidemiol Biomarkers Prev 2005; 14: 1333-5. http://cebp.aacrjournals.org/content/14/5/1333.long [cited 20 Dec 2011].

46. Babkoff H, French J, Whitmore J, Sutherlin R. Single-dose bright light and/or caffeine effect on nocturnal performance. Aviat Space Environ Med 2002; 73: 341-50.

47. Wright KP Jr., Badia P, Myers BL, Plenzler SC, Hakel M. Caffeine and light effects on nighttime melatonin and temperature levels in sleep-deprived humans. Brain Res 
1997; 747: 78-84. http://www.sciencedirect.com/science/article/ pii/S0006899396012681 [cited 28 Dec 2011].

48. Ursing C, Wikner J, Brismar K, Röjdmark S. Caffeine raises the serum melatonin level in healthy subjects: an indication of melatonin metabolism by cytochrome P450(CYP)1A2. J Endocrinol Invest 2003; 26: 403-6.

49. MacKenzie T, Comi R, Sluss P, Keisari R, Manwar S, Kim J, et al. Metabolic and hormonal effects of caffeine: randomized, double-blind, placebo-controlled crossover trial. Metab Clin Exp 2007; 56: 1694-8. http://www.sciencedirect.com/ science/article/pii/S0026049507002752 [cited 28 Dec 2011].

50. Shilo L, Sabbah H, Hadari R, Kovatz S, Weinberg U, Dolev S, et al. The effects of coffee consumption on sleep and melatonin secretion. Sleep Med 2002; 3: 271-3. http://www.sciencedirect. com/science/article/pii/S1389945702000151 [cited 29 Dec 2011].

51. Sherman H, Gutman R, Chapnik N, Meylan J, le Coutre J, Froy O. Caffeine alters circadian rhythms and expression of disease and metabolic markers. Int $\mathrm{J}$ Biochem Cell Biol 2011; 43: 829-38. http://www.sciencedirect.com/science/article/ pii/S1357272511000641 [cited 20 Apr 2012].

52. von Gall C, Garabette ML, Kell CA, Frenzel S, Dehghani F, Schumm-Draeger PM, et al. Rhythmic gene expression in pituitary depends on heterologous sensitization by the neurohormone melatonin. Nat Neurosci 2002; 5: 234-8. http://www.nature. com/neuro/journal/v5/n3/abs/nn806.html [cited 20 Apr 2012].

53. Babey AM, Palmour RM, Young SN. Caffeine and propranolol block the increase in rat pineal melatonin production produced by stimulation of adenosine receptors. Neurosci Lett 1994; 176: 93-6. http://www.sciencedirect.com/science/article/pii/ 0304394094908796 [cited 5 Jan 2012].

54. Kot M, Daniel WA. Caffeine as a marker substrate for testing cytochrome P450 activity in human and rat. Pharmacol Rep 2008; 60: 789/97. http://www.if-pan.krakow.pl/pjppdf/ 2008/6_789.pdf [cited 5 Jan 2012].

55. Wright KP Jr., Myers BL, Plenzler SC, Drake CL, Badia P. Acute effects of bright light and caffeine on nighttime melatonin and temperature levels in women taking and not taking oral contraceptives. Brain Res 2000; 873: 310-7. http: www.sciencedirect.comsciencearticlepii/S0006899300025579 [cited 5 Jan 2012].

56. Webley GE, Leidenberger F. The circadian pattern of melatonin and its positive relationship with progesterone in women. $\mathrm{J}$ Clin Endocrinol Metab 1986; 63: 323-8.

57. Brun J, Claustrat B, David M. Urinary melatonin, LH, oestradiol, progesterone excretion during the menstrual cycle or in women taking oral contraceptives. Acta Endocrinol 1987; 116: $145-9$

58. Hilli J, Korhonen T, Turpeinen M, Hokkanen J, Mattila S, Laine $\mathrm{K}$. The effect of oral contraceptives on the pharmacokinetics of melatonin in healthy subjects with CYP1A2 g.-163C > A polymorphism. J Clin Pharmacol 2008; 48: 986-94. http:// jcp.sagepub.com/content/48/8/986.long [cited 12 Jan 2012].

59. Cohen Engler A, Hadash A, Shehadeh N, Pillar G. Breastfeeding may improve nocturnal sleep and reduce infantile colic: potential role of breast milk melatonin. Eur J Pediatr 2012; 171: 729-32. http://www.ncbi.nlm.nih.gov/pubmed/22205210 [cited 16 Jan 2012].

60. Aparicio S, Garau C, Esteban S, Nicolau MC, Rivero M, Rial RV. Chrononutrition: use of dissociated day/night infant milk formulas to improve the development of the wake-sleep rhythms. Effects of tryptophan Nutr Neurosci 2007; 10: 137-43.

61. Cubero J, Narciso D, Aparicio S, Garau C, Valero V, Rivero M, et al. Improved circadian sleep-wake cycle in infants fed a day/ night dissociated formula milk. Neuro Endocrinol Lett 2006; 27 : 373-80.
62. Valtonen M, Niskanen L, Kangas AP, Koskinen T. Effect of melatonin-rich night-time milk on sleep and activity in elderly institutionalized subjects. Nord J Psychiatry 2005; 59: 217-21. http://informahealthcare.com/doi/abs/10.1080/08039480510023034 [cited 29 Dec 2011].

63. Ekman AC, Leppäluoto J, Huttunen P, Aranko K, Vakkuri O. Ethanol inhibits melatonin secretion in healthy volunteers in a dose-dependent randomized double blind cross-over study. J Clin Endocrinol Metab 1993; 77: 780-3.

64. Röjdmark S, Wikner J, Adner N, Andersson DE, Wetterberg L. Inhibition of melatonin secretion by ethanol in man. Metab Clin Exp 1993; 42: 1047-51. http://www.sciencedirect.com/ science/article/pii/002604959390021F [cited 29 Dec 2011].

65. Rupp TL, Acebo C, Carskadon MA. Evening alcohol suppresses salivary melatonin in young adults. Chronobiol Int 2007; 24: 463-70. http://informahealthcare.com/doi/abs/10.1080/ 07420520701420675 [cited 29 Dec 2011].

66. Danel T, Touitou Y. Alcohol consumption does not affect melatonin circadian synchronization in healthy men. Alcohol 2006; 41: 386-90. http://alcalc.oxfordjournals.org/content/41/4/ 386.long [cited 29 Dec 2011].

67. Hartman TJ, Mahabir S, Baer DJ, Stevens RG, Albert PS, Dorgan JF, et al. Moderate alcohol consumption and 24-hour urinary levels of melatonin in postmenopausal women. J Clin Endocrinol Metab 2012; 97: E65-8. http://www.ncbi.nlm.nih. gov/pubmed/22013099 [cited 20 Dec 2011].

68. Stevens RG, Davis S, Mirick DK, Kheifets L, Kaune W. Alcohol consumption and urinary concentration of 6-sulfatoxymelatonin in healthy women. Epidemiology 2000; 11: 660-5.

69. Peres R, do Amaral FG, Madrigrano TC, Scialfa JH, Bordin S, Afeche SC, et al. Ethanol consumption and pineal melatonin daily profile in rats. Addict Biol 2011; 16: 580-90. http:// onlinelibrary.wiley.com/doi/10.1111/j.1369-1600.2011.00342.x/abstract [cited 29 Dec 2011].

70. Fournier I, Ploye F, Cottet-Emard JM, Brun J, Claustrat B. Folate deficiency alters melatonin secretion in rats. J Nutr 2002; 132: 2781-4. http://jn.nutrition.org/content/132/9/2781.long [cited 20 Dec 2011].

71. Bediz CS, Baltaci AK, Mogulkoc R. Both zinc deficiency and supplementation affect plasma melatonin levels in rats. Acta Physiol Hung 2003; 90: 335-9. http://www.akademiai.com/ content/n5538412344u6667/ [cited 20 Dec 2011].

72. Belviranli M, Baltaci AK. The relation between reduced serum melatonin levels and zinc in rats with induced hypothyroidism. Cell Biochem Funct 2008; 26: 19-23. http://onlinelibrary.wiley. com/doi/10.1002/cbf.1384/abstract [cited 20 Dec 2011].

73. Billyard AJ, Eggett DL, Franz KB. Dietary magnesium deficiency decreases plasma melatonin in rats. Magnes Res 2006; 19: 157-61. http://www.jle.com/en/revues/bio_rech/mrh/ e-docs/00/04/27/62/resume.phtml [cited 20 Dec 2011].

74. Morton DJ. Possible mechanisms of inhibition and activation of rat $\mathrm{N}$-acetyltransferase (EC 2.3.1.5.) by cations. J Neural Transm 1989; 75: 51-64.

75. Morton DJ, James MF. Effect of magnesium ions on rat pineal N-acetyltransferase (EC 2.3.1.5) activity. J Pineal Res 1985; 2: 387-91.

76. Schernhammer ES, Feskanich D, Niu C, Dopfel R, Holmes MD, Hankinson SE. Dietary correlates of urinary 6sulfatoxymelatonin concentrations in the Nurses' Health Study cohorts. Am J Clin Nutr 2009; 90: 975-85. http://www.ncbi. nlm.nih.gov/pmc/articles/PMC2744623/?tool=pubmed [cited 20 Dec 2011].

77. Luboshitzky R, Ophir U, Nave R, Epstein R, Shen-Orr Z, Herer $P$. The effect of pyridoxine administration on melatonin secretion in normal men. Neuro Endocrinol Lett 2002; 23: 213-7. 
78. Muñoz-Hoyos A, Amorós-Rodríguez I, Molina-Carballo A, Uberos-Fernández J, Acuña-Castroviejo D. Pineal response after pyridoxine test in children. J Neural Transm 1996; 103: $833-42$.

79. Murck H, Steiger A. Mg2 + reduces ACTH secretion and enhances spindle power without changing delta power during sleep in men - possible therapeutic implications. Psychopharmacology (Berl) 1998; 137: 247-52. http://www.springerlink. com/content/77pakxdx8nde33fq/ [cited 28 Dec 2011]

80. Turgut M, Yenisey C, Akyüz O, Ozsunar Y, Erkus M, Biçakçi T. Correlation of serum trace elements and melatonin levels to radiological, biochemical, and histological assessment of degeneration in patients with intervertebral disc herniation. Biol Trace Elem Res 2006; 109: 123-34.

81. Catalá A. The function of very long chain polyunsaturated fatty acids in the pineal gland. Biochim Biophys Acta 2010; 1801: 95-9. http://www.sciencedirect.com/science/article/ pii/S1388198109002480 [cited 5 Jan 2012]

82. Lavialle M, Champeil-Potokar G, Alessandri JM, Balasse L, Guesnet P, Papillon C, et al. An (n-3) polyunsaturated fatty acid-deficient diet disturbs daily locomotor activity, melatonin rhythm, and striatal dopamine in Syrian hamsters. J Nutr 2008;
138: 1719-24. http://jn.nutrition.org/content/138/9/1719.long [cited 5 Jan 2012].

83. Zaouali-Ajina M, Gharib A, Durand G, Gazzah N, Claustrat B, Gharib C, et al. Dietary docosahexaenoic acid-enriched phospholipids normalize urinary melatonin excretion in adult (n-3) polyunsaturated fatty acid-deficient rats. J Nutr 1999; 129: 2074-80. http://jn.nutrition.org/content/129/11/2074.long [cited 5 Jan 2012].

84. Cornu C, Remontet L, Noel-Baron F, Nicolas A, Feugier-Favier $\mathrm{N}$, Roy P, et al. A dietary supplement to improve the quality of sleep: a randomized placebo controlled trial. BMC Complement Altern Med 2010; 10: 29. http://www.ncbi.nlm.nih.gov/pmc/ articles/PMC2901361/?tool=pubmed [cited 12 Jan 2012].

\section{*Katri Peuhkuri}

Institute of Biomedicine, Pharmacology

Medical Nutrition Physiology

P.O. Box 63

000 I 4 University of Helsinki

Finland

Tel: +358919125366

Email: katri.peuhkuri@helsinki.fi 